Journal of Sustainable Development of Transport and Logistics

journal home page: http://jsdtl.sciview.net

\begin{tabular}{|c|c|}
\hline \begin{tabular}{|l} 
Journal of \\
Sustainable \\
酐elopment of \\
Transport and \\
Zuogistics \\
\end{tabular} & $\begin{array}{l}\text { Redziuk, A., Klymenko, O., Ageiev, V., \& Novikova, A. (2017). The concept and the } \\
\text { development plan of national transport model of Ukraine. Journal of Sustainable Development } \\
\text { of Transport and Logistics, 2(1), 16-28. doi:10.14254/jsdtl.2017.2-1.2. }\end{array}$ \\
\hline
\end{tabular}

Redziuk, A., Klymenko, O., Ageiev, V., \& Novikova, A. (2017). The concept and the development plan of national transport model of Ukraine. Journal of Sustainable Development Logistics

\title{
The concept and the development plan of national transport model of Ukraine
}

\section{Anatoly Redziuk *, Oleksiy Klymenko **, Volodymyr Ageiev ***, Alla Novikova $* * * *$}

* The State Enterprise "State Road Transport Research Institute",

57 Peremohy Ave, Kyiv, 03113, Ukraine

e-mail: aredzuk@insat.org.ua

PhD, Director

** The State Enterprise "State Road Transport Research Institute",

57 Peremohy Ave, Kyiv, 03113, Ukraine

e-mail: aklimenko@insat.org.ua

PhD, Deputy Head on Scientific and Technological Development of Road Vehicle Testing Centre, Deputy Head of Research Laboratory of Fuels and the Environment

*** The State Enterprise "State Road Transport Research Institute",

57 Peremohy Ave, Kyiv, 03113, Ukraine

e-mail: vageev@insat.org.ua

PhD, First Deputy Director

**** The State Enterprise "State Road Transport Research Institute",

57 Peremohy Ave, Kyiv, 03113, Ukraine

e-mail: anovikova@insat.org.ua

Dr, Deputy Director



Article history:

Received: March, 2017

1st Revision: April, 2017

Accepted: May, 2017

\section{DOI:}

10.14254/jsdtl.2017.2-1.2
Abstract: For discussion it is given the proposals to the a draft concept of national transport model of Ukraine with brief description of the goal, objectives, functions, constraints, architecture, basic principles and a priority action plan for establishment of the national transport model of Ukraine and a respective data center as a basic infrastructure component to ensure creation and subsequent functioning of the national transport model, as well as to enable continuous informational support of the transport industry to enhance its efficiency.

Keywords: national transport model of Ukraine, data center of national transport model, strategic planning of transport development, national transport policy 


\section{Introduction}

A national transport model (NTM) is a powerful tool that applied by developed countries of the world for informational and analytical support of strategic planning, development, implementation and monitoring of implementation of transport policy.

Existence of NTM is today one of indispensable conditions for attracting investments in reconstruction and development of transport infrastructure, as well as in realization of the transit potential of a country. It is, in particular, in accordance with decision-making standards regarding investment projects, adopted by the international financial institutions.

The purpose of the article is to open a discussion among science and industry community of the given proposals to the draft concept of NTM in the case of Ukraine, given in the form of a high-level document with the aim to present in a condensed form and without unnecessary details a general view on the goals, objectives, functions, constraints, architecture, basic principles and a priority action plan for development of NTM and respective data center (the Data Center of NTM) as a basic infrastructure component to ensure creation and subsequent functioning of NTM, as well as to enable continuous informational support of transport industry to enhance its efficiency.

\section{The definition of a NTM and the purpose of its creation}

In general definition, a national transport model (NTM) is a virtual reflection (analogue) of a transport system as an integral component of economy, realized on the basis of methods of mathematical simulation with the use of computers and specialized software, including geographic information systems and many other instruments, which allows predicting its state correspondingly to certain performance indicators, according to different scenarios of development.

Forward-looking indicators of functioning of the transport system may include, in particular, distributed in space and the time characteristics of flows of goods and passengers by various modes of transport, which are functions of many factors, including general tendencies in economy, overall transport policy, as well as separate management decisions and other.

Results of a mathematical simulation at the level of NTM are for example:

- forecasts of transport demand (transport demand for passengers and cargo to different locations) and transport offers, a promising load of transport network (distribution of traffic flows on: traffic intensity within separate parts of a network; types of transport; types of freight and other);

- forecasts of time of delivery of cargoes and transportation of passengers and related costs for different scenarios;

- identification of the elements of the transport network, where the traffic load in the future (and when) will become excessive, compared with their capacity;

- multidimensional assessment of effectiveness and consequences of introduction of new infrastructure and rehabilitation and modernization of existing one in the transport sector, as well as introduction of new transport technologies (for example, intelligent transportation systems, multi-modal systems and other) in particular:

- comparison of different variants of development of the transport infrastructure and identification of priority areas (the most important investment projects);

- solution for optimization tasks (including on resource allocation);

- forecasting macroeconomic, social, environmental impacts and direct income from the operation of infrastructure (for example, toll roads, with the assessment of the optimal level of payment), determination of payback period and other;

- determined impact of individual projects and overall transport policies on a performance of the transport system and national economy (and some regions of a country) under different scenarios (for example, prediction of impact of tariff policy and regulatory tools on overall volume and distribution of traffic between different modes of transport, etc.);

- forecasted consumption of energy resources and emissions of pollutants (for instance, specific energy consumption by transport is an important indicator of its efficiency and competitiveness); 
- determining the best options for integrating and improving the interaction between different modes of transport and other.

In Fig. 1, as an example of a graphical representation of the results of transport modeling, it's shown forecasts of congestion in the UK in accordance with one of the scenarios considered by the UK`s Department for Transport (GOV.UK, 2015).

In Fig. 2, as an example of the results of transport modeling, it`s given a simplified reconstruction of truck transportation of cereals through the territory of Ukraine in 2012 within a demonstration project, carried out by the SYSTRA, Corporate Solutions in 2015 (The training materials..., 2015).

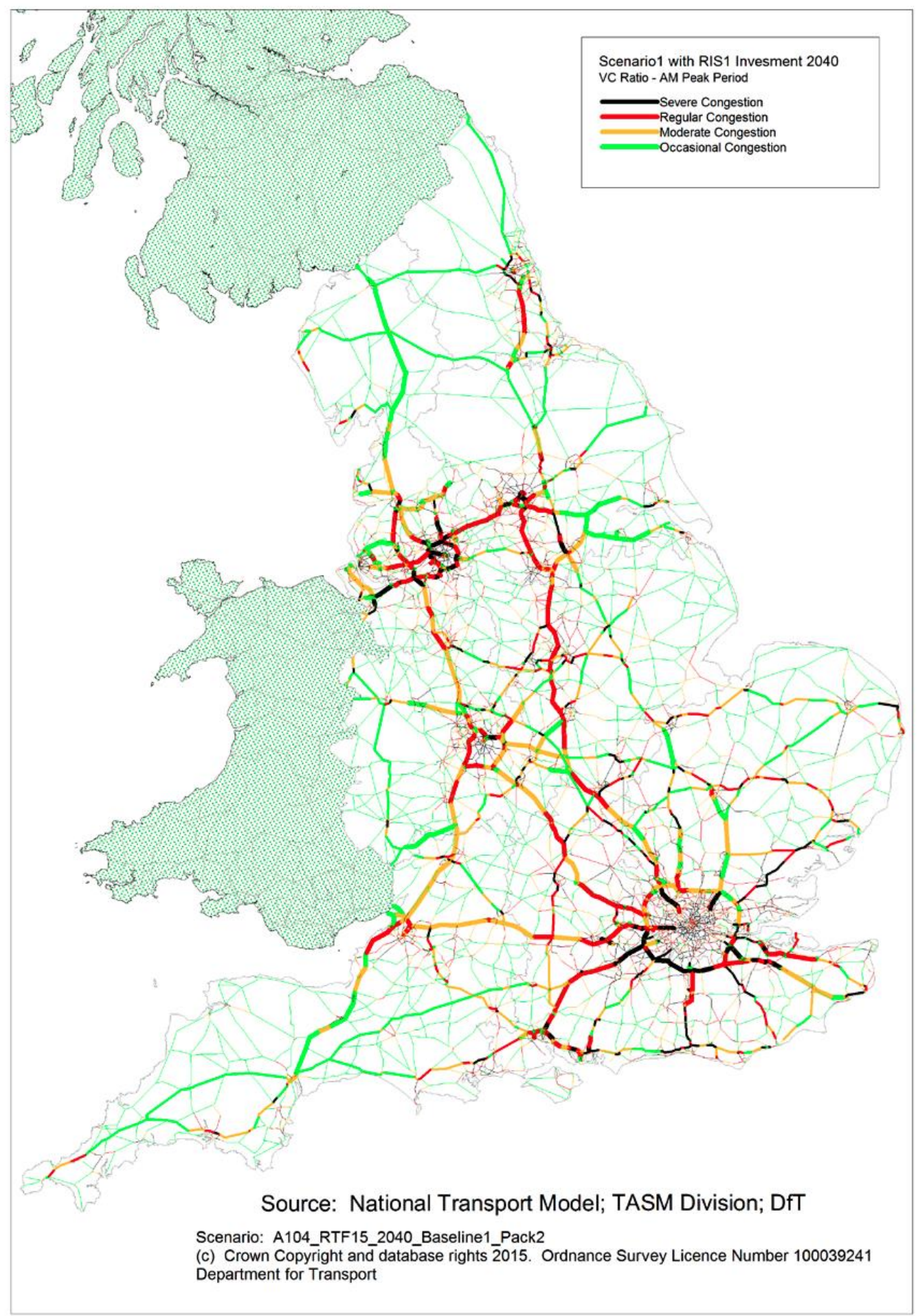

Fig. 1. Forecasts of congestion in the UK in accordance with one of the scenarios that are considered

Resource: (GOV.UK, 2015). 


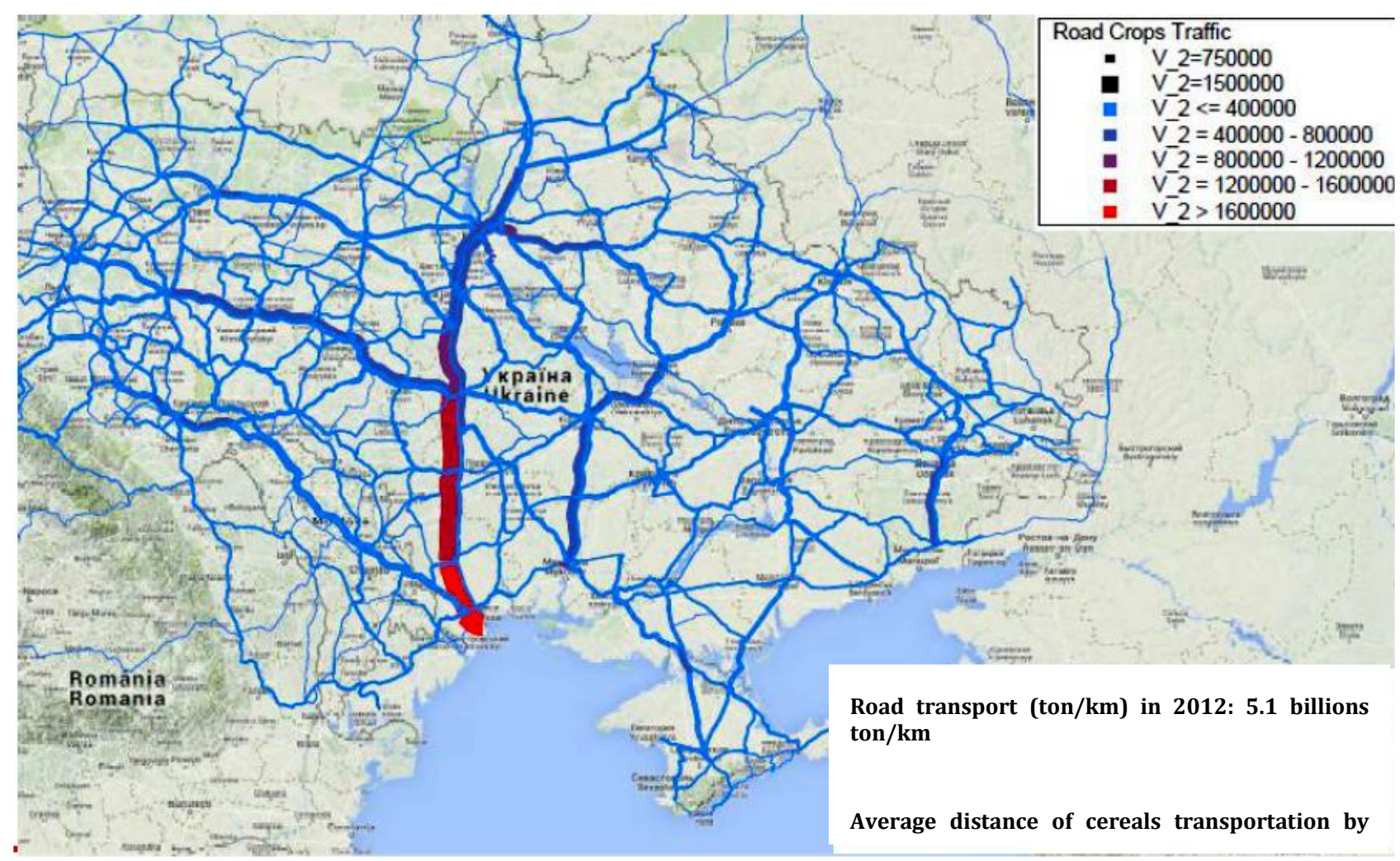

Fig. 2. Reconstruction (it`s simplified representation in the framework of the demonstration project) of transportation by road of cereals on the territory of Ukraine in 2012

Resource: (The training materials..., 2015)

The overall aggregated goal of creation of NTM can be defined as improving efficiency of management and decision-making in the field of development and support of the national transport system.

The main objectives of NTM (and a respective data center as a basic infrastructure component to ensure establishment and further functioning of NTM), thus, are:

- informational and analytical support of the process of making operational and strategic multivariant decisions of management bodies in accordance with various economic development scenarios, a study (prediction) of possible consequences of management decisions;

- feasibility study of investment projects in accordance with the practice of the EU and the requirements of potential investors (including international financial institutions) to attract investments in reconstruction and development of the transport system;

- analysis of ways to improve the efficiency, reliability, accessibility, quality of services and safety of the transport system functioning, reducing consumption of energy and emission of pollutants;

- realization of transit potential, integration of the transport system into the European and global transport network.

\section{Link between creation of the Ukrainian NTM and the policy documents of the Government}

The establishment of NTM and a respective data center must be done, in particular, according to the Action Plan for the Implementation of the Association Agreement between Ukraine, on the one hand, and the European Union, the European atomic energy Community and their member States, on the other hand, for 2014-2017 period, approved by Decree of the Cabinet of Ministers of Ukraine of 17.09.2014 No. 847 "On the implementation of the Association Agreement between Ukraine and the EU, the European atomic energy Community and its member States, on the other hand" (Decree..., 2014) in terms of infrastructure to ensure implementation of paragraph 277, related to the 
development, implementation and further usage of NTM in the course of planning and implementation of the strategy of development of the transport infrastructure, as well as:

- paragraph 278, on creation of automated information-and-analytical system of collecting and analyzing data related to the transportation of passengers and goods, including transit;

- paragraph 286, on creation of a single (common) state electronic register of road carriers;

- paragraph 275, regarding collection of baseline data for analysis and development at the national level of an Integrated development plan of logistics to ensure the creation of a network of logistics centers, optimizing the transportation, etc.;

-paragraph 274, on collection of baseline data for analysis and justification of the main directions of implementation of the Transport strategy of Ukraine for the period till 2020;

- paragraph 279, on strengthening the institutional capacity of the Ministry of Infrastructure in the field of transport infrastructure development policy, in particular through the implementation of best practices of the EU in the formation and implementation of the state policy to ensure stable and efficient functioning of the transport system;

-paragraph 272, on development, improvement and updating projects (drafts) of the Concept of the National (priority) transport network of Ukraine and the Programme of development of the National (priority) transport network of Ukraine.

\section{Role of NTM in the management system of the Ministry of infrastructure of Ukraine and in development of the transport system (as it is prescribed in the legislation)}

The national transport model (NTM) of Ukraine is necessary to ensure implementation by the Ministry of infrastructure of Ukraine the objectives, prescribed in the Regulations on the Ministry of Infrastructure of Ukraine, approved by Resolution of the Cabinet of Ministers of Ukraine of June 30, 2015 No 460, in particular:

- prioritization, ensuring the formation and implementation of the state policy in the transport sector, in the road sector and development of transport infrastructure, traffic safety, and other;

- approval and execution of forecast and program documents on development of aviation, automobile, railway, marine and river transport, road facilities, postal services, underground and urban electric transport development and development of national transport networks (international transport corridors) in Ukraine, ensuring integration of the national transport system to the European and global transport networks;

- participation to the extent provided by legislation, in the formation and implementation of the uniform state economic, tariff, investment, credit and social policy in the fields of transport and road services, and also formation within the competence of the priorities of development of science-and-technology and innovation-investment policy;

- direction, coordination and implementation of methodological support of activities on implementation of the tasks of mobilization preparation in the field of transport;

- coordination and methodical maintenance of carrying out of actions for preparation of a single (common) transport system of Ukraine for steady functioning of technical cover, restoration of critical facilities and structures of defense value of the unified transport system of Ukraine in the special period and measures on transfer of transport, transport infrastructure in appropriate operation in the case of the introduction in the State of the special (military) period;

- organization within the authority defined by the law and implementation of public policies to reduce the harmful effects of transport on the environment;

- ensuring effective and targeted use of the state budget funds, etc.

\section{The priorities of NTM of Ukraine at the initial stage of its creation}

\subsection{The limitations of the model at the initial stage of development:}

The NTM should provide answers to questions regarding the optimal transport policy and the priority directions of development of the transport sector as an integrated system, where simultaneously are considered different types (modes) of transport and, in particular, their 
interaction, and other aspects. In practical terms, the NTM consists of several separate mathematical models, which are interrelated. In accordance with world experience, the creation of NTM is a highly sophisticated task, which requires the introduction of certain restrictions in respect of areas of the real world and the phenomena that it reflects, and levels of detail (level of disaggregation).

The model will cover primarily the following types (modes) of transport:

-road transport;

-railway transport;

-inland water transport.

Marine and aviation types (modes) of transport will also certainly be considered as an important integral part of the NTM of Ukraine. However, at the first phase of the NTM development, it is considered appropriate to focus efforts first on detailed study of infrastructure development of road, railway and inland waterway transport. But, again, it must be noted that marine and aviation modes influence on and interdependence with other modes should not be underestimated the national and regional scales even at this initial stage of NTM development.

The model at the initial stage will cover types of traffic: import, export, transit, domestic and long-distance on (covering the major cities, large and/or strategically important transport nodes) trunk transportation of cargo (for separate types of cargo) and passengers.

Urban and suburban transportation in the early stages of development of NTM of Ukraine are not directly considered, except for the modeling of key transport hubs and other infrastructure with a large share of "local" traffic flows, which will have a significant impact on the conditions of operation of the main (arterial) transportation and, sure, operation of the state transportation system as a whole.

Urban and suburban transportation, in accordance with accepted around the world practice, are subject of a separate transport models for cities and regional models, solving problems on a local level with a high degree of detail and in accordance with a set of specific tasks of "local" significance. Of course, local models, in the course of their development, will be integrated by a specific way into the NTM and will be considered in the future as a part of a single consistent integrated system.

The main base year, data of which are used for calibration and confirmation of the adequacy of the model, by comparing results of mathematical simulation with observations of reality, is presumably 2015 (it`s to be confirmed by the results of the analysis of available input data and its quality in different periods of time). In addition to main base year ("static" verification of model) it can be used other different periods of time in the past for mentioned purposes, including reflection dynamics of the processes.

The time horizon of forecasting for NTM is long-term (according to the EU`s strategy) and medium-term forecast up to 2025 (as well as other periods that will be developed for individual tasks).

\subsection{The sequence of the tasks and the results that are needed to be obtained in the early stages of development of NTM:}

1. The matrix of transport correspondences in the base year, the assessment of transport demand and information on its satisfaction.

2. The description of transport infrastructure (including GIS maps) in the base year (it's assessment of transport proposals).

3. The mathematical model of the transport system that is calibrated in the base year (it`s as holistic view of the situation in the base year).

4. Inventory and analysis of major infrastructure projects that are already in the planning stages, design and implementation concerning roads, railroads, inland water ways and other infrastructure, as well as technologies (intermodal transport, and other), which provide backbone transportation.

5. On the basis of forecasts of socio-economic development under different scenarios, creation the models of demand for the main (backbone) transportation of goods and passengers in the period of forecasting.

6. Determination of the influence of existing infrastructure projects in transport industry and the transport policy under different scenarios of socio-economic development on envisaged transport network load (it's distribution of traffic flows on separate sites of a network and types (modes) of transport) with the identification of "bottlenecks". 
7. Development of proposals on possible infrastructure projects and options for policies based on optimization models in the forecast period with assessment of key performance indicators of industry, energy consumption, impact of transport on the environment, general economic indicators and the like.

8. Definition of long-term priorities of development of Ukrainian transport system, as well as definition of priorities for medium-term period, till 2025.

\section{The principles of construction and architecture of the data center to support NTM}

Establishment of NTM requires a large amount of detailed input data, in particular data regarding transport system activity, transport infrastructure and the overall economy (it should be discussed in separate publications with the right level of detail). Here in this article it's sufficient to simply note that the most of the input data sets, that are needed to construct a NTM, do not exist today in Ukraine. Furthermore, a significant part of the existing statistical or administrative data are either incomplete or do not reflect the real situation.

The key infrastructure component for the construction of NTM (and in the future in the process of gradual development of a unified informational environment of the transport system) is creation of a respective data center (the Data Center of NTM).

In the hierarchical structure of the informational environment of the industry (Fig. 3) Data Center of NTM predominantly operates with aggregated data from the top (high-level) management level, to provide informational, analytical and scientific support for the formation and implementation of state policy in the sector, as well as managerial decision-making.

The informational environment of technological integration of various modes of transport and the transport process participants (technological level) is one of the basic sources of data for the Data Center of NTM. On the other hand, the Data Center of NTM can also be a platform for the progressive realization of the effective informational interaction of participants of transport and logistics and related processes, access to relevant reference data and services, development of intelligent transport systems, harmonization and standardization, and other.

Informational environment of transport services and customer's informational services (consumer level) is also a source of primary source data for the Data Center of NTM.

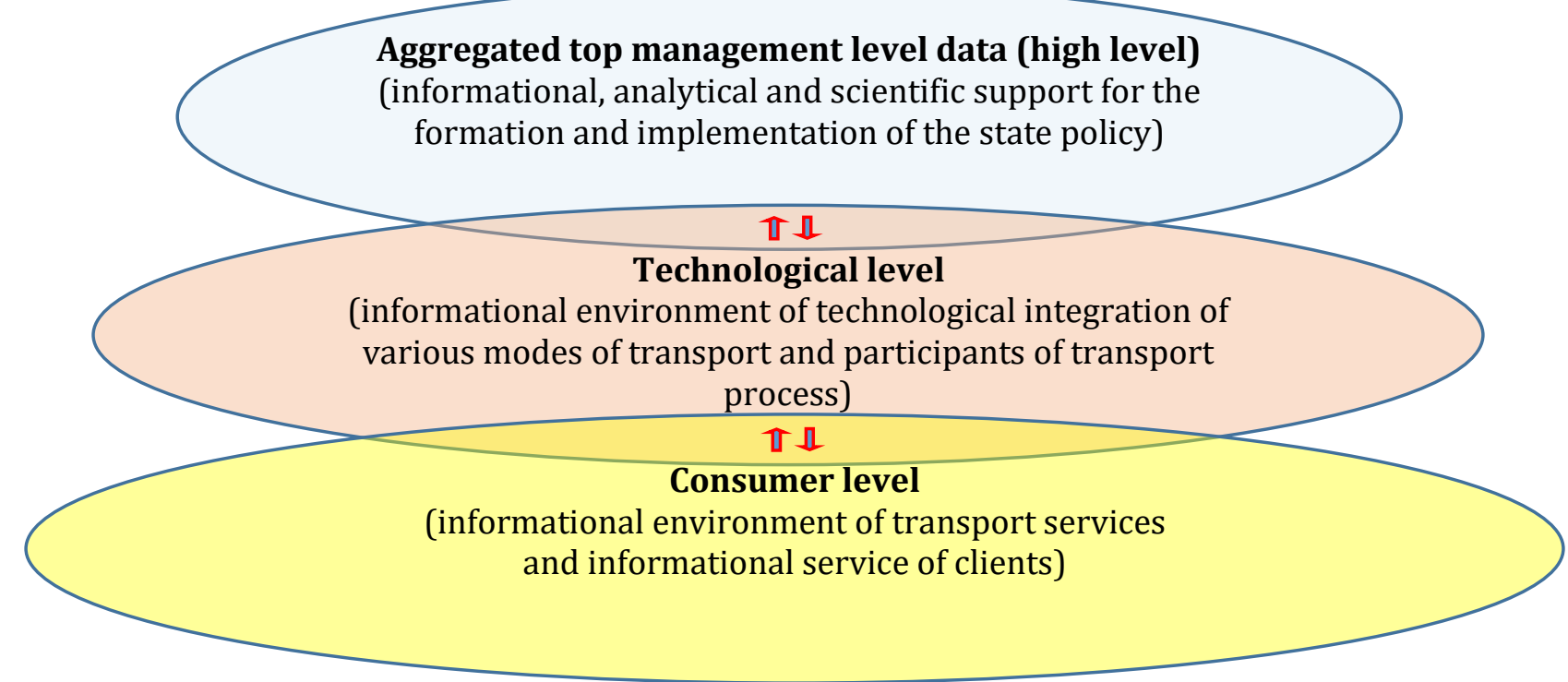

Fig. 3. A simplified representation of the hierarchical structure of the informational environment of the industry

Basic principles of building the Data Center of NTM should include, in particular, the following:

1. Integration and consolidation of data sets of the transport system that are required for transport modeling and the creation of NTM is implemented in a single (common) informational 
environment, which is updated at regular intervals, supporting chronology, metadata, and should to be unified and reliable source of data.

2. The existing and future industry and corporate informational systems and the Data Center of NTM that is under formation, are independent elements that communicate and combine on a contractual basis by providing an integration components. Thus, a single (uniform) informational space of the transport system, that is gradually formed, is constructed as a distributed system, that is decentralized.

3. The infrastructure of the Data Center of NTM should provide features for gradual placing of a uniform structured database system of objects and subjects of the transport system, events, material, informational, financial flows and other.

4. Access to resources of the Data Center of NTM and informational services are provided by various consumer groups on free and partly on paid basis (the latter relates to the main source of development, sustainable functioning of information technology infrastructure, the maintenance of the NTM, development of individual transport models for analysis, feasibility study and optimization of infrastructure projects in industry and other).

5. It should be provided equal rights of access to information and equal competitive conditions for each defined specific group of data consumers.

From a technical point of view, the process of designing and building of the Data Center of NTM should satisfy the following principles:

1. It should be considered the experience of leading countries of the world in this field.

2. The structure and format of data should be compatible with similar Europe-wide informational systems.

3. Orientation at the predominant use of standard interfaces and informational protocols.

4. Orientation at modern methods and approved by leading countries technical solutions regarding integration of informational systems.

5. Orientation at the use of proven and widely implemented by leading countries of the universal programming systems of the leading manufacturers of the world (including in the fields of software products for data processing, mathematical modeling (transport models), operation with GIS systems, etc.)

6. Basic architecture of the Data Center of NTM should be open, scalable, to ensure the continuity and the evolution of the system, phased development and implementation according to available resources and current tasks.

7. Architecture of the Data Center of NTM should be flexible and able for gradual integration with other informational systems, in particular, the state electronic government systems.

8. The system must to be protected against unauthorized operation and ensure uninterrupted and continuous operation.

The requirements for building the Data Center of NTM are not limited to the above. Complete, in particular, the functional representation of the architecture of the Data Center of NTM, which will provide solution of tasks and achievement of goals set out in this concept, will be developed in terms of involvement of all stakeholders and specialists of information technology of companies in the fields of informational systems, data centers creation and other.

\section{A priority action plan}

Development and support of functioning of NTM and the Data Center of NTM requires the direct participation of all stakeholders with the involvement of relevant resources.

It is proposed to implement the following priority actions for the further development of detailed conceptual and program documents on development of the NTM and the Data Center of NTM:

1) development, public study and discussion with participation of wide science and industry community, and adoption of the first edition of the concept of NTM on high level;

2) presenting high-level concept for approval to the involved executive authorities and subjects, collecting additional data (including inventory, study of the structure and content of the existing and future databases, informational flows, process flow diagrams, needs, infrastructure projects, constraints, etc.), obtaining comments and suggestions from all stakeholders; 
3) development, coordination and approval of Detailed Concept with the involvement of specialized professionals in the field of information technologies and other related spheres;

4) development, coordination and approval of the Strategic Action Plan (policy document) to ensure implementation of the approved Detailed Concept of NTM of Ukraine.

The mentioned above Strategic Action Plan should be approved at the level of the Cabinet of Ministers of Ukraine, and it should include mechanisms of adequate the state financial support of such a project.

Further work on construction of the Data Center of NTM, creating and operation of NTM of Ukraine, will be done according to the approved Strategic Action Plan and involved resources.

It is require the solution of such priorities (presented below in aggregate form):

1. Development and usage of mechanisms for financing of creation and further sustainable operation of the Data Center of NTM, research units for transport modeling and other components of the system (in particular, creation of an appropriate business model).

2. Development of institutional capacities to ensure functioning of the Data Center of NTM and transport modeling (including staff training and creation of conditions for its operation, creation, commissioning and maintenance of relevant information technology infrastructure).

3. Development and implementation of a legal framework regarding data sharing.

4. A gradual unification of the existing and future state, departmental, corporate and other informational systems.

5. Further development of domestic specialized software for automation of processes of gathering, processing and transmission of data.

6. Commencing gradual inventory (detailed description) of transport system of Ukraine in accordance with the practice and legislation of the EU countries.

7. Receiving, in defined format data that are needed to create and ensure functioning of the NTM. It includes reproduction (synthesis) on the basis of methods of mathematical simulation of the missing but important data regarding infrastructure and operation of the industry and other data needed as input for NTM.

8. Creation, configuration and verification of isolated pilot models and overall NTM of Ukraine for selected base year.

9. Definition of policies, actions and infrastructure projects that require predicting the effects of implementation and development of corresponding mathematical models for a certain (defined) period of forecast.

10. Modeling (forecasting in accordance with different scenarios), analysis, refinement and optimization of different options for the development of the transport system of Ukraine.

11. Development of a scientifically grounded strategy of development of transport system of Ukraine.

12. Further operation of the Data Center of NTM, NTM, units for transport modeling as a tool for solving current and future tasks of the industry and achieving settled goals.

The most complicated and, in fact, a key transport mode - an element in building and operation of the Data Center of NTM, as well as in creation and operation of NTM of Ukraine - is road transport, within which there are large systemic problems with gathering and/or reconstruction of original data sets that are necessary for modeling.

The strategic development plan of the State Enterprise "State Road Transport Research Institute" for the medium term 2014 - 2020, approved by Order of the Ministry of Infrastructure of Ukraine of 23.10.2014 No. 539 (Ministry of Infrastructure of Ukraine, 2014), within the direction of scientific, analytical and expert support of Ukrainian road transport activities, has included establishment on the basis of the State Enterprise "State Road Transport Research Institute" of information system to support Ukrainian road transport industry for improvement of the efficiency of its functioning. Accordingly, on the basis of available facilities, expertise and scientific potential of the State Enterprise "State Road Transport Research Institute" as a multidisciplinary research institute under the management of the Ministry of Infrastructure of Ukraine, it should be created the basic elements of the Data Center of NTM, as well as NTM of Ukraine.

The State Enterprise "State Road Transport Research Institute" has experience in the development of aggregated national and detailed regional transport models, including that used for reconstruction and prediction of structure of the fleet (Fig. 4), the volume of traffic, the consumption of motor fuels, pollutant's emissions (Fig. 5, Fig. 6) and condition of pollution of urban environment (Fig. 
7) depending on different scenarios of socio-economic development of the country and the state regulation in these areas.



Fig. 4. Example of simplified, aggregated view of the evolution in the period 1990-2016 of ecological structure (reconstruction) of the active part of the road vehicle fleet in Ukraine Resource: (Study of the impact on emissions..., 2016)

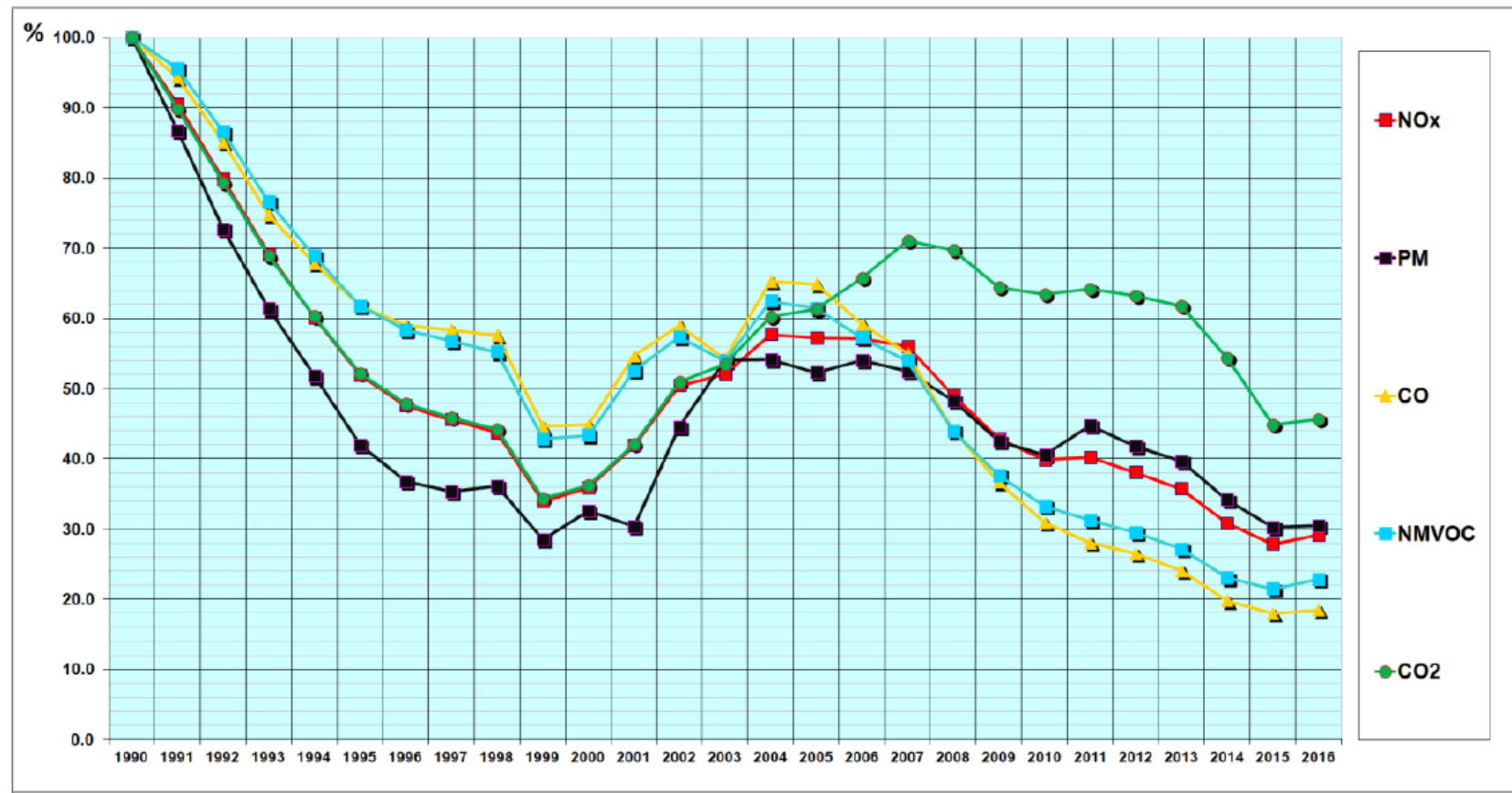

Fig. 5. Reconstruction by methods of mathematical simulation of emissions from road vehicles on the territory of Ukraine of carbon dioxide (CO2), nitrogen oxides (NOx), particulate matter (PM2.5), carbon monoxide (CO) non-methane volatile organic compounds (NMVOC) Resource: (Study of the impact on emissions..., 2016) 


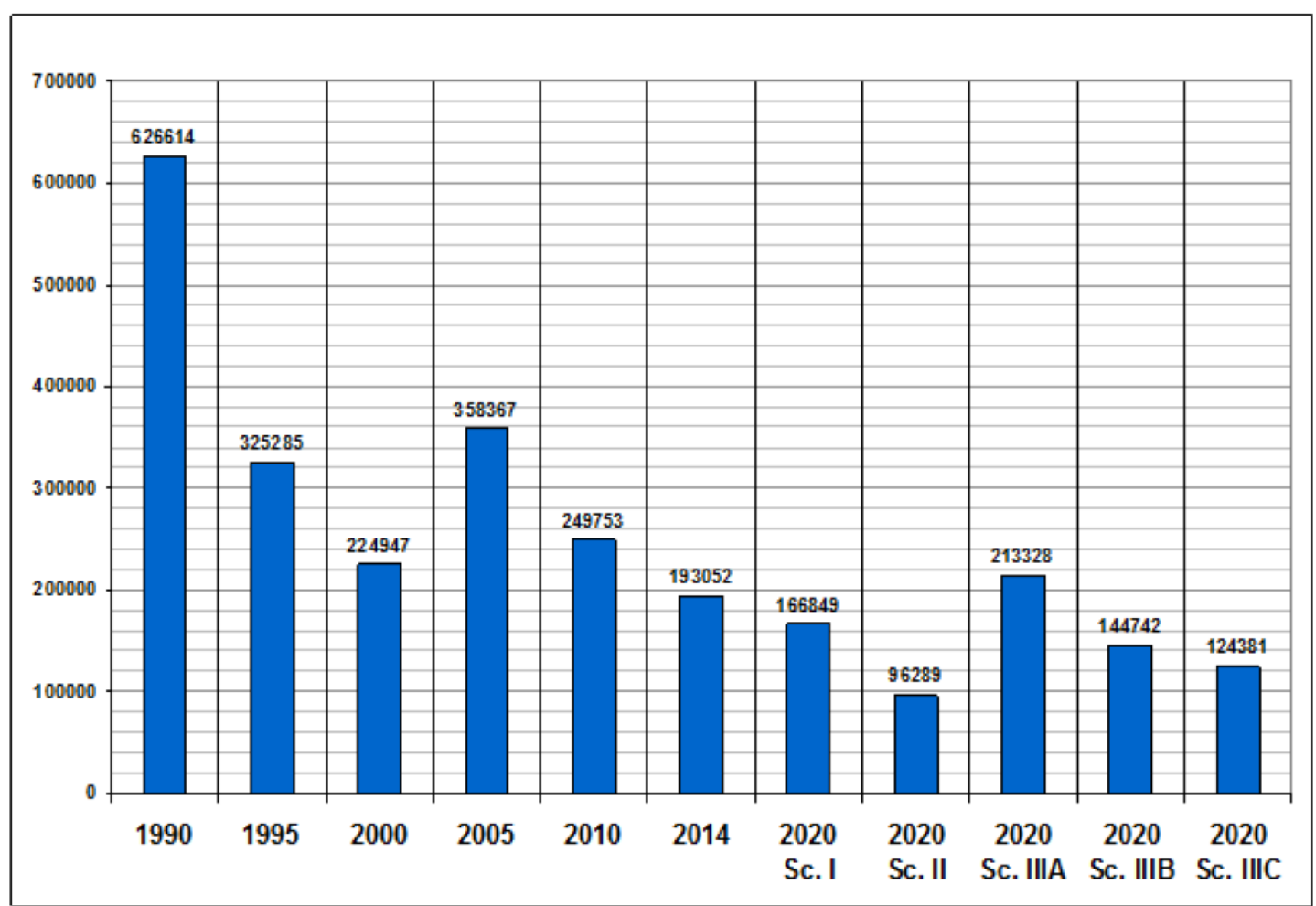

Fig. 6. Reconstruction in the period 1990-2014 and projected emissions $(t)$ of oxides of nitrogen (NOx) from road vehicles on the territory of Ukraine under different scenarios of socio-economic development and public regulation

Resource: (Study of the impact on emissions..., 2015)

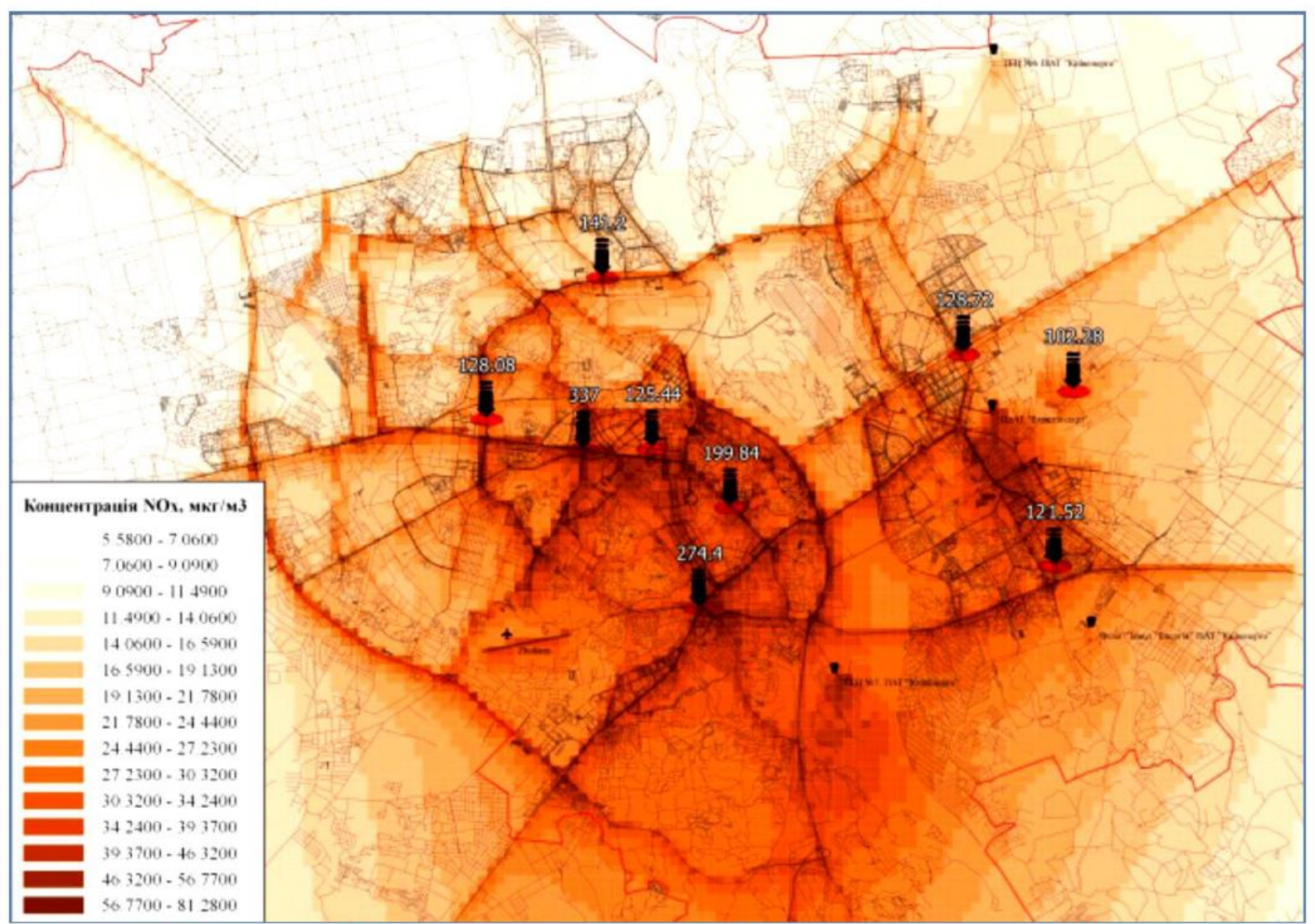

Fig. 7. An example of mathematical modeling of pollution in the city of Kyiv (the background concentration of nitrogen oxides and the concentrations on some selected streets) Resource: (Development of a mathematical model of quality, 2015) 
For the time being on the basis of the State Enterprise "State Road Transport Research Institute" it is created the working groups on development and support of functioning of the Data Center of NTM and NTM of Ukraine, data collection and processing (including development of appropriate data processing algorithms), transport analytics, economic analysis, transport modeling in various areas, geographic information systems, visualization of simulation results and in other areas.

\section{Conclusions}

It should again be noted that the construction of the Data Center of NTM and creation of NTM are complex and large-scale tasks that require significant resources, involving a large number of stakeholders and have strongly pronounced inter-departmental character. There is a long list of executive bodies and entities that are data sources and consumers of the Data Center of NTM, as well as consumers of the results that should provide NTM. And the article gives proposals in the form of high-level overview of draft concept of NTM in the case of Ukraine, as an invitation for open discussion of this issue among all stakeholders.

Consideration of other aspects of the creation of NTM, including a detailed description of the structure of necessary baseline data, information flows between potential participants in the process, as well as approaches to collection and/or synthesis of data, is the subject of separate publications.

\section{Appendix A. Supplementary material}

Supplementary data associated with this article can be found, in the online version, at http://jsdtl.sciview.net

\section{Funding}

State Enterprise "State Road Transport Research Institute", Ukraine.

Comments and suggestions on the draft concept of Ukraine's NTM, as well as proposals for cooperation in this field, please send to the address of the State Enterprise "State Road Transport Research Institute”: 57 Peremohy Ave, Kyiv, 03113, Ukraine or NTM@insat.org.ua).

\section{Citation information}

Redziuk, A., Klymenko, O., Ageiev, V., \& Novikova, A. (2017). The concept and the development plan of national transport model of Ukraine. Journal of Sustainable Development of Transport and Logistics, 2(1), 16-28. doi:10.14254/jsdtl.2017.2-1.2.

\section{References}

Decree of the Cabinet of Ministers of Ukraine of 17.09.2014 No. 847. (2014). "On the implementation of the Association Agreement between Ukraine and the EU, the European atomic energy Community and its member States, on the other hand".

Development of a mathematical model of quality of atmospheric air of the city on the basis of European technology THOR-Air-PAS to assess the effectiveness of road infrastructure, traffic organization and projects of urban development. (2015). 2015 interim report of the State Enterprise "State Road Transport Research Institute" for research work. Number of the State registry of research work: 0115U006028.

GOV.UK. (2015). Road Traffic Forecasts 2015. The Department for Transport, the UK Government, Great Minster House, London. Retrieved from https://www.gov.uk/government/publications/road-traffic-forecasts-2015

Ministry of Infrastructure of Ukraine. (2014). The strategic development plan of the State Enterprise "State Road Transport Research Institute" for the medium term 2014 - 2020, approved by order of the Ministry of Infrastructure of Ukraine from 23.10.2014 No. 539.

Study of the impact on emissions of harmful substances in atmospheric air of the structure of the road vehicle fleet of Ukraine. (2016). 2016 interim report of the State Enterprise State "Road 
Transport Research Institute" for research. Number of the State registry of research work: 0112 U001736.

Study of the impact on emissions of harmful substances in atmospheric air of the structure of the road vehicle fleet of Ukraine. (2015). 2015 interim report of the State Enterprise State "Road Transport Research Institute" for research. Number of the State registry of research work: 0112 U001736.

The training materials regarding transport simulation, which carried out in Ukraine by the SYSTRA. Corporate Solutions in 2015.



Journal of Sustainable Development of Transport and Logistics (ISSN: 2520-2979) is published by Scientific Publishing House "CSR", Poland, EU and Scientific Publishing House "SciView", Poland, EU

Publishing with JSDTL ensures:

- Immediate, universal access to your article on publication

- High visibility and discoverability via the JSDTL website

- Rapid publication

- Guaranteed legacy preservation of your article

- Discounts and waivers for authors in developing regions

Submit your manuscript to a JSDTL at http://jsdtl.sciview.net/ or submit.jsdtI@sciview.net 